\title{
The effectiveness of acceptance and commitment therapy on reduction of obesity and body image
}

\author{
Farideh Dokaneheei FARD ${ }^{1, *}$, Behrooz MEHRABIAN ${ }^{2}$, Zeinab BorOON $^{3}$, Momeneh GHADERI ${ }^{4}$, \\ Sara YOUSEFI ${ }^{5}$, Salva Shamseddini LORY ${ }^{6}$ \\ ${ }^{1}$ Phd, Assistant Professor, Department Of Counseling, Islamic Azad University, Roudehen Branch, Roudehen, Iran \\ ${ }^{2}$ Phd Student, Department Of Counseling, Islamic Azad University, Roudehen Branch, Roudehen, Iran \\ ${ }^{3}$ Phd Student, Department Of Counseling, Islamic Azad University, Roudehen Branch, Roudehen, Iran \\ ${ }^{4}$ Phd Student, Department Of Counseling, Islamic Azad University, Roudehen Branch, Roudehen, Iran \\ ${ }^{5} \mathrm{Ma}$, Department Of Counseling, Young Researchers And Elite Club, Roudehen Branch, Islamic Azad University, \\ Roudehen Iran \\ ${ }^{6}$ Phd Student, Department Of Counseling, Young Researchers And Elite Club, Roudehen Branch, Islamic Azad \\ University, Roudehen, Iran \\ *Corresponding Author: Dr Farideh Dokaneheei Fard; Email: F_Dokaneheeifard@ Yahoo.com
}

\begin{abstract}
The purpose of this research was to study the effectiveness of acceptance and commitment therapy on reduction of obesity and body image. This was a quasi-experimental study with pretest and post-test and a control group. The population in this study included all patients who referred to the center of weight loss and nutrition clinics in area number 1 of Tehran city. 30 people were chosen among those people who were considered obese based on the MBI index. They were divided into two groups. The experimental group underwent eight sessions of treatment but the control group did not undergo any intervention. The results of data analysis using analysis of covariance indicated that acceptance and commitment therapy is effective on reducing obesity and body image. So we can use this method as an effective way to help people reduce these problems.
\end{abstract}

Keywords: obesity, treatment based on acceptance and commitment, ACT

\section{Introduction}

According to the latest statistics, a third of the country's population, equivalent to 25 million people are overweight or obese, which of these numbers $43 \%$ are men and $57 \%$ are women. 8 million of the 25 million suffer from obesity and 17 million are overweight. People who are obese or overweight are different in various cities, so that in Tehran city the statistics in the male population and female population is $70 \%$ to $60 \%$ (Roustaei, 1394).

Although global statistics show that the world suffers from this big and fundamental problem but in Iran huge wave of weight loss surgeries and procedures show disturbing statistics. Body image is a multidimensional concept that at least contains perceptual, emotional, cognitive and 
behavioral body experience aspects (Bijari, 1388). Body image, is not related to what the person is really like meaning there are not related to a person's actual appearance, but it is related to the individual's special relationship with one's body, especially to their beliefs, perceptions, thoughts, feelings and activities of individual which are associated with his physical appearance (Pedram, 1389). Since body image is the internal representation of one's external appearance and this representation covers physical and perceptional dimensions and attitudes towards them, obese people often have difficulty accepting their body image, (Brozekowski and Bayer, 2005). The main aspect of these attitudes include evaluation components (body dissatisfaction), investment (external self-schemas and their apparent importance of the ideal internalization) and affect (Cash and Pruzinsky, 1990, 2002, quoting Cash et al., 2004). Since appearance, is an important part of one's identity and appears immediately in in social situations, dealing with others, the importance of this personality structures is very obvious. Of course, the amount of importance and attention of individuals to this domain is different in various classes. For example, research has shown that the importance of body image and physical attractiveness among women and young people are more than other segments of society. Nonetheless, when gender and age differences are taken into account, sometimes this situation is disturbed, it becomes a concern and leaves unfavorable effects on different aspects of one's life. For example, impaired body image can be a causal risk factor in the development of eating disorders, or foreground of body dysmorphic disorder (Rozen and Ramirez, 1998).

The best treatment in overweight and obesity is a treatment that simultaneously, includes dietary modification, change in physical activity and behavioral therapy. Also depression, mental illness and even small changes in daily mood can affect people's nutrition in addition to other social and health aspects. Many people become anorexic or bulimic when faced with nerve problems in stressful situations and witness significant increase or decrease in weight, in a short time. Diseases such as bulimia and anorexia nervosa are rooted in behavioral and psychological disorders. If obese individuals with extensive psychopathology and those who are in the midst of a life crisis attempt to lose weight, it should be with great care and supervision. One of these cares, is a psychological care (Kaplan and Sadock, 2007). Among these treatments, acceptance and commitment therapy is one of the waves. This treatment was introduced by Steven Hayes and colleagues at the beginning of the 1980s and was known by the acronym ACT. ACT has roots in the deep philosophical theory called functional contextualism and theoretically it is based on relational frame theory (RFT), which explains the process of the creation of suffering by the mind and useless methods to deal with it, as well as the underlying alternative approach to these areas. ACT uses metaphors, training experience and logical contradiction to escape the verbal content and the use of steady communication with the flow of constant experience in the present. The main component of the ACT include acceptance, diffusion, self as a background, connecting with the present, value and commitment (Izadi and Abedi, 1392). This treatment is one of the behavioral treatments based on mindful attention which its effectiveness has been clear for the treatment of a wide range of clinical situations. People in this treatment get aware of most of the wrong features associated with the self and self- relational issues. This treatment can 
deal differently with the problem of obesity and find a solution to a lifetime of weight control (Assar, 1392). Imagine a treatment where no effort is done for reducing the symptoms, but symptom decrease is the lateral product of doing it. ACT aims to create a rich and meaningful life while the individual accepts the available inevitable suffering. ACT, short term for action is interesting because this treatment is effective when the action is driven by our deepest values and are committed only when we are absolutely ready. It is only through conscious action that we can build a meaningful life. Of course, when we began to make an effort to build a life we are faced with all sorts of obstacles in the form of unwanted, unpleasant inner experiences (thoughts, images, feelings, sensations, impulses and memories) (Izadi and Abedi, 1392).

Methodology, statistical population, sample and sampling method

The statistical population in this study included all patients who referred to the center of weight loss and nutrition clinics in area 1 of Tehran city, which among them, 30 people who were considered obese by the MBI index were selected by convenience sampling. They were divided into two groups of 15, each. The experimental group underwent 8 sessions of ACT treatment but the control group did not undergo any treatment.

Criteria for inclusion in this study were: being overweight to be considered obese, according to the MBI index, having the same diet and nutrition, according to an instruction by the doctor, avoiding the use of supplements and weight loss, lack of absence from the training classes.

\section{Method of performance:}

ACT treatment was carried out within two months (eight sessions, of 90-minutes) for the experimental group and the treatment protocol (adapted from Jurasive article, 2013 quoted Zahab, 1394) is presented in Table 1.

Table 1: A brief description of ACT treatment sessions

\begin{tabular}{|c|c|}
\hline $\begin{array}{c}\text { First } \\
\text { session }\end{array}$ & $\begin{array}{l}\text { Introduction of treatment, informed consent of a person to complete the treatment process and } \\
\text { acquaintances with treatment goals, investigating the concept of obesity and weight loss and the causes } \\
\text {.(of obesity, implementation of pre-test (taking a record of the initial weight of the experimental group }\end{array}$ \\
\hline $\begin{array}{l}\text { Second } \\
\text { session }\end{array}$ & $\begin{array}{l}\text { The concept of behavior, eating behavior, causes of overeating and necessity of behavior change to } \\
\text { improve health and quality of life }\end{array}$ \\
\hline $\begin{array}{c}\text { Third } \\
\text { session }\end{array}$ & $\begin{array}{l}\text { Understanding the concept of acceptance, providing metaphors related to intellectual ruminations and } \\
\text { tendency to eat, investigating the concept of stress and its relationship with overeating }\end{array}$ \\
\hline $\begin{array}{l}\text { Fourth } \\
\text { session }\end{array}$ & $\begin{array}{l}\text { Understanding the concept of value, value } \\
\text { the practice of mindfulness }\end{array}$ \\
\hline $\begin{array}{c}\text { Fifth } \\
\text { session }\end{array}$ & $\begin{array}{l}\text { Setting goals and introduction of fragm } \\
\text { mindfulness, Representation of the conce }\end{array}$ \\
\hline $\begin{array}{c}\text { Sixth } \\
\text { session }\end{array}$ & followi \\
\hline $\begin{array}{l}\text { Seventh } \\
\text { session }\end{array}$ & $\begin{array}{l}\text { Addressing to act responsibly, self-observing exercise, commitment to do the presented exercises and } \\
\text { understanding of suffering and patience to do the exercises presented and understanding the concept of } \\
\text { suffering and patience towards not eating }\end{array}$ \\
\hline $\begin{array}{l}\text { Eighth } \\
\text { session }\end{array}$ & $\begin{array}{l}\text { Preparation for completion of session, reviewing exercises, And implementation of the post-test (t } \\
\text { (a record of secondary weight of the experimental group }\end{array}$ \\
\hline
\end{tabular}


Bulletin de la Société Royale des Sciences de Liège, Vol. 85, 2016, p. 1571 - 1577

Table 2: The Mean and standard deviation of the scores of pre-test and post-test groups

\begin{tabular}{|c|c|c|c|c|c|c|c|c|}
\hline \multicolumn{4}{|c|}{ Control group } & \multicolumn{4}{|c|}{ Experimental group } & \multirow{3}{*}{ variable } \\
\hline \multicolumn{2}{|c|}{ Post-test } & \multicolumn{2}{|c|}{ Pre-test } & \multicolumn{2}{|c|}{ Post-test } & \multicolumn{2}{|c|}{ Pre-test } & \\
\hline sd & $\mathrm{M}$ & sd & $\mathrm{M}$ & sd & $\mathrm{M}$ & $\mathrm{sd}$ & $\mathrm{M}$ & \\
\hline 0.207 & 1.185 & 0.223 & 1.163 & 0.220 & 0.803 & 0.273 & 1.17 & obesity \\
\hline 0.239 & 1.165 & $0 / 257$ & 1.132 & 0.264 & 1.07 & 0.186 & 0.587 & $\begin{array}{l}\text { Body } \\
\text { image }\end{array}$ \\
\hline
\end{tabular}

For studying the significance of observed differences, using covariance analysis, data normality was studied using Shapiro - Wilk test. Given the fact that the significance level for all variables of obesity and body image was larger than 0.05 , therefore null hypothesis of Shapiro-Wilk test based on no difference of data normality from the normal distribution was confirmed. According to statistics obtained from Levine test to check the homogeneity of variances for each variable were observed in four tests related to each variable, which Levine's significance for all variables was greater than 05.0. Therefore, the assumption of equality of variances were observed and confirmed and analysis of covariance can be used.

As it is seen in Table 2 at a significance level of $(\mathrm{p}<0.0001)$ and the degree of freedom of 1 and $\mathrm{F}=2.97, \mathrm{~F}=26.6$ and $\mathrm{F}=17.40, \mathrm{ACT}$ has caused significant reduction in the obesity rate and body image. Eta square (effect size) is another indicator that should be considered. Eta square represents percentage of score variance of the dependent variable that is created by the implementation of the experimental action. Eta square for the obesity variable is equivalent to 26.0 and body image is equivalent to 0.49 , meaning 0.26 of obesity scores, 68.0 and 49.0 of body image scores results from the implementation of ACT as an independent variable.

Table 3: Summary of covariance analysis of obesity and body image in groups

\begin{tabular}{|r|r|r|r|r|r|r|r|}
\hline eta & Sig. & $\mathrm{F}$ & $\mathrm{MS}$ & $\mathrm{df}$ & $\mathrm{SS}$ & & \\
\hline 0.26 & 0.006 & 2.97 & 127.4 & 1 & 127.4 & Between group & obesity \\
\hline 0.07 & 0.57 & 5.07 & 217.25 & 1 & 217.25 & pretest & \\
\hline- & - & & 42.85 & 19 & 814.3 & error & \\
\hline 0.68 & 0.0001 & 26.6 & 564.37 & 1 & 564.37 & Between group & Body image \\
\hline 0.11 & 0.57 & 4.11 & 87.23 & 1 & 87.23 & pretest & \\
\hline- & - & & 21.22 & 19 & 403.24 & error & \\
\hline
\end{tabular}

\section{Discussion and conclusion}

The aim of this research was to study the effectiveness of acceptance and commitment therapy in reduction of obesity and body image in individuals with overweight. The results indicated that ACT is effective in controlling obesity and satisfaction of the body image. The findings of the research are in line with the findings of Jurasive (2013), Lylz (2009), Sadeghi (1388), Fouladvand (1391), Shapiro \& Schwartz (2000), Davidson and et al(2003), Carlson et al (2003), Singh et al (2004) and Mousavian (1388).To explain these findings, we can say that given that 
most people who diet to lose weight will still arrive to their previous weight gradually over a year and their austerity remains fruitless, not enough medical treatments are developed to solve this problem. Now days there are treatments that have faults and shortcomings. Some medications and treatments can be useful in the short term but after a while they began their unpleasant side effects on the individual and their loss is more than their gain (Beck, 2007).

In fact, ACT treatment with an emphasis on mindfulness practice has shown that this approach makes individuals aware about the roots of the disorder and its mechanism in the brain. It prevents one from getting anxious, focuses on one's thoughts and desires in the conscious state and gives the individual an opportunity not to choose the repetition of actions or thoughts, and its rumination in reducing anxiety and to think about the biological roots of the disease. Although technology, development and human progression has allowed humans to treat many diseases without the need for any physical movement so their time could be saved, but it must be acknowledged that still many diseases and mental disorders can be solved in the shadow of the therapist short-term guidance and training (Mousavian, 1391). This treatment leads to a cognitive shift in the thought and actions of a person and it profits from the principle of conditional reinforcement. Thus, the suffering person for going to the next step aims to see oneself at the next step and the desire to continually step above causes the gradual improvement of an individual and at the same time continues the individual's treatment with calmness and awareness, and solves their deficiencies and problems in the face to face meetings. Also Rachman and Hodghson (2008) argue that this treatment is a suitable method for people who go through negative and anxious emotional states about their health and appearance. These exercises with awareness control of moment to moment and non-judgmental in the form of step by step, self-control, self-regulation and monitoring one's own actions will lead one towards recovery. Cognitive treatment based on acceptance and commitment, provides an opportunity for people to observe their physical sensations, cognitions, perceptions and emotions without any judgment, and to accept them and understand that not necessarily the thoughts coincide with reality.

\section{References}

Adachi, y. (2005). behavior therapy for obesity, behavioral helts, fukuoka japan 11-48.

Amiri, Hamid. (2012).The effectiveness of physical education and life promotion programs on diet therapy success in people with obesity. Unpublished Master's thesis, Allameh Tabatabaei University, Faculty of Education and Psychology, Clinical Psychology

Asadi, Seifullah. (2011) obesity. Tehran: Ashjae

Assar, Jallal. (2013). Overweight and obesity. Tehran: Superior Man 
Bulletin de la Société Royale des Sciences de Liège, Vol. 85, 2016, p. 1571 - 1577

Athari, Amina (2011) The incidence of general and abdominal obesity in girl's primary school students in Mashad city. Unpublished Master's thesis, Ferdowsi University of Mashhad, Faculty of Physical Education, Physical education

Bakh, P.D, Muran (2011). Act in practice (translated by Sarah Kamali, Niloofar Kianrad) (2016). Tehran: Arjmand

Beck, G. (2009). Get lean and stay lean (translation by Majid Shahrabi). (1393). Tehran: Tamisheh

Bokharie, Masoud. (2013). Obesity a different approach. Tehran: Gutenberg.

Cameron, D. (2010). Obesity species (Translator Farzaneh Sheikh al-Islami) (2011). Tehran: Alhuda publications

Curtis, Anthony (2005) Health Psychology (translated by Ali Fathi-Ashtiani, Hadi Azimi) 1388. Tehran: Beasat

Ekhtiari, Hamed. (2013) I am a happy obese. Tehran: Mehrsa.

Fallahi, Ibrahim, Abbas zadeh, Maryam, Tarrahi, Mohammad Javad; Natri, Afshin. (2008). The effect of weight loss diet alone and in combination with Satrux on weight control in overweight and obese women. Medical Journal of Tabriz University of Medical Sciences, Volume 28, No. 3, p. 85-88

Habib Zadeh. (2013). The efficacy of acceptance and commitment therapy on reduction of dissatisfaction of girl's body image. Unpublished master's thesis, Islamic Azad University of Rudehen. Psychology faculty, clinical psychology

Judy, V (2012). Healthy diet in women (translation of Elham Ghods). (2013).Tehran: Talaieh

Jurasio, a. shaw, j. (2013).acceptance and commitment therapy as a novel treatment for eating disorder.Behavior modification, 459-489

Lillis, j. and Hayes, s, and Bunting, k. Masuda, a. (2009).Teaching acceptance and mindfulness to improve the lives of the obese. The society of behavioral medicine, 59-69.

Maddah Shourcheh, Raheleh. (2014). The effectiveness of cognitive behavioral group therapy in increase of quality of life, body satisfaction and reducing depression in people with obesity. Unpublished master's thesis, Ferdowsi University of Mashhad, Faculty of Psychology and Educational Sciences, Clinical psychology

Mousavi, Fatemeh. (2011). The rate of general and local obesity prevalence in adults of Rasht city. Unpublished master's thesis, University of Guilan, Faculty of Physical Education, Physical education 
Bulletin de la Société Royale des Sciences de Liège, Vol. 85, 2016, p. 1571 - 1577

Roosen, m. safer, d. cebola, a.(2012). Group dialectical behavior therapy adapted for obese emotional esters. nutr hosp issn 0212- 1611

Sadeghi, Kheirollah. (2009). The effectiveness of cognitive behavioral therapy in treating patients with obesity. Journal of Psychiatry and Clinical Psychology, Vol. XVI, No. 2, Summer 1389

Sadock, B. Sadock, Y. (2007). Psychiatry summary (translation of Nosratullah pour Afkari) (2010).tehran: Shahrab

Sasanfar, Hamid Reza (2010). The effectiveness of group cognitive therapy and diet on weight loss in obese women. Unpublished master's thesis, University of Kurdistan, Faculty of Humanities, Psychology

Sher, Mary. (2011). The effectiveness of cognitive - behavioral therapy in the treatment of girls with obesity, research on psychological health, Volume sixth, second edition, Summer 1391. 